\title{
ГЕНОТИПИРОВАНИЕ ПОЛИРЕЗИСТЕНТНОЙ МИКРОФЛОРЫ ОРИТ КАК МЕТОД ВЫБОРА ОПТИМАЛЬНЫХ ЛЕЧЕБНЫХ И ЭПИДЕМИОЛОГИЧЕСКИХ РЕШЕНИЙ
}

\section{GENOTYPING OF POLYRESISTANT MICROFLORA OF THE ICU AS A METHOD OF SELECTING OPTIMAL THERAPEUTIC AND EPIDEMIOLOGICAL SOLUTIONS}

A. Avramov

S. Tsarenko E. Zinina

Summary. Purpose and objectives: To study the microbial landscape of two independent intensive care units of one hospital, taking into account the following factors: antibiotic resistance, spread in the external environment and biological environments. To study the genetic characteristics of the prevailing bacteria. To trace the dynamics of the change of microorganisms in patients transferred to a specific intensive care unit from other departments and other hospitals. Material and methods: 101 samples collected in 2 intensive care units in the period 2018-2019 with an interval of 6 months were studied. The samples were both material obtained from patients, staff, and elements of the hospital environment. All samples were subjected to phenotypic and molecular genetic analysis, determination of antibiotic resistance, isolation and amplification of DNA, multilocus sequencing (MLST).

Results and conclusions: The predominance of Gram-negative flora, microbes of the KAP group (K. pneumoniae, A. baummanii, P. aerouginosae) was revealed. In the course of MLST sequencing, it was shown that for each intensive care unit there is a different, predominant genotype of the pathogen. Strains of the same type of microorganisms in different departments have different genotypes and different levels of sensitivity to antibiotics.

The analysis of antibiotic resistance showed that the dominant genotypes of the branches have the broadest resistance among all strains. It is shown that the strains introduced from other hospitals are not detected in any samples after 14 days. They are completely suppressed and replaced by the local flora. However, we have obtained data confirming the possibility of transferring nosocomial strains between departments by medical personnel.

Based on the data obtained, we assume that the most promising epidemiological measures aimed at preventing the transfer of bacteria within and between ICUs. For the prevention of the transmission of K. pneumoniae and P. aeruginosa, the most important measures are personal hygiene of personnel, for A. baumannii - careful treatment of environmental objects is of paramount importance.

\author{
Аврамов Александр Александрович \\ Врач анестезиолог-реаниматолог, ФГАУНМИЦ \\ «Лечебно-реабилитационный центр» МЗ РФ \\ avramovmsu@gmail.com \\ Царенко Сергей Васильевич \\ Заместитель главного врача по анестезиологии \\ и реаниматологии, ГБУЗ «ГКБ № 52 ДЗМ г. Москвы \\ S9637501492@yandex.ru \\ Зинина Елизавета Павловна \\ Врач анестезиолог-реаниматолог, ФГАУ НМИЦ \\ «Лечебно-реабилитачионный чентр» МЗ РФ \\ epzinina@gmail.com
}

Аннотация. Цель и задачи: Изучить микробный пейзаж двух независимых отделений реанимации одного госпиталя сучетом следующих факторов: антибиотикорезистентности, распространения во внешней среде и биологических средах. Изучить генетические особенности превалирующих бактерий. Проследить динамику смены микроорганизмов у пациентов, переведенных в конкретное отделение реанимации из других отделений и иных больниц.

Материал и методы: Изучен 101 образец, собранный в 2 отделениях реанимации в период 2018-2019 с интервалом в 6 мес. 0бразцы представляли собой как материал, полученный от пациентов, так и от персонала, и из элементов больничной среды. Все образцы подвергнуты фенотипическому и молекулярно-генетическому анализу, определению антибиотикорезистентности, выделению и амплификации ДНК, мультилокусному секвенированию (MLST).

Результаты и выводы: Выявлено преобладание Грам отрицательной флоры, микробов группы KАР (K.pneumoniae, A.baummanii, P.aerouginosae). В ходе MLST секвенирования показано, что для каждого отделения реанимации существует свой, преобладающий генотип возбудителя. Штаммы одного и того же вида микроорганизмов в разных отделениях имеют разные генотипы и разные уровни чувствительности к антибиотикам.

Анализ антибиотикорезистентности показал, что доминирующие генотипы отделений обладают наиболее широкой устойчивостью среди всех штаммов. Показано, что привнесённые из других госпиталей штаммы не определяются ни в каких пробах уже через 14 дней. Их полностью подавляет и замещает местная флора. Однако, нами были получены данные, подтверждающие возможность переноса внутрибольничных штаммов между отделениями медицинским персоналом.

На основе полученных данных мы предполагаем, что наиболее перспективны эпидемиологические мероприятия, направленные на предупреждение переноса бактерий внутри и между ОРИТ. Для профилактики переноса К. pneumoniae и P. aeruginosa важнейшими являются меры личной гигиены 
Keywords: antibiotic resistance, genotyping, nosocomial infections, k. pneumoniae, a. baumannii, p. aeruginosa Multilocus sequencing. персонала, для A. baumannii - первостепенное значение имеет тщательная обработка предметов окружающей среды.

Ключевые слова: антибиотикорезистентность, генотипироварие, внутрибольничные инфекции, k.pneumoniae, a.baumannii, p.aeruginosa Мультилокусное секвенирование.

\section{Введение}

O тделения реанимации и интенсивной терапии (ОРИТ) являются своеобразной экологической «нишей», успешно занимаемой различными микроорганизмами. Причиной указанного обстоятельства являются значительная длительность госпитализации пациентов и необходимость инвазивных манипуляций. Согласно данным крупного мультицентрового однодневного исследования EPIC II 51\% пациентов имели какую-либо форму инфекции, а 71\% - получали антибиотики. Основными возбудителями среди грамотрицательных микроорганизмов стали Acinetobacter и Pseudomonas, среди грамположительных - Staphylococcus. 64\% всех инфекций составили поражения органов дыхания.

В аналогичном российском исследовании установлено, что 34,1\% пациентов ОРИТ имеют инфекционное заболевание какой-либо локализации. Основными возбудителями были грамотрицательные микроорганизмы, среди которых доминировали Enterobacteriacea (52,7\%) и неферментирующие палочки Pseudomonas aeruginosa (29,9\%) и Acinetobacter spp. (15,7\%) [2].

Особое напряжение создает нарастающая резистентность микробной флоры с распространением мультирезистентных штаммов (чувствительность только к 1-2 антибиотикам) и панрезистентных (с отсутствием всякой чувствительности) [18].

Для того, чтобы разработать способы решения данной проблемы, необходимо понимание причин нарастания полирезистентности к антибиотикам (АБ). Современные исследования позволяют их разбить на две группы. Первая группа - это нарушения диагностического процесса и лечебной тактики. Сюда относится назначение АБ по неинфекционным причинам, нерациональная АБ-профилактика, неточный выбор препаратов для стартовой эмпирической АБ-терапии, использование АБ в неоправданно малых дозах, затянутые сроки применения АБ [24]. Развернутый анализ этой группы причин выходит за рамки настоящей работы.

Вторая группа причин антибиотикорезистентности санитарно-эпидемиологические. К ней можно отнести перенос резистентных микроорганизмов внутри ОРИТ, занос из других отделений больницы и иных лечебных учреждений. Передача микроорганизма с «воспитанной» предшествующим назначением антибиотиков резистентностью от больного к больному кажется само собой разумеющейся и дает основания для разработки путей профилактики. Тем не менее, анализ доступной литературы демонстрирует неожиданные факты. Большинство исследователей, обсуждающих перенос бактерий, строят свои рассуждения на здравом смысле и косвенных данных [19]. Обычно основанием для эпидемиологических заключений является выявление одинакового спектра антибиотикорезистентности у микроорганизмов, высеваемых от разных больных одного или нескольких ОРИТ. Последнее обстоятельство дает основания предполагать, что клиницисты имеют дело с одним и тем же микроорганизмом. Однако современная микробиология утверждает, что обоснованность данного предположения может быть подтверждена или опровергнута только при генетическом анализе высеваемых бактерий [20].

Для уточнения данного обстоятельства и разработки потенциально эффективных путей профилактики межи внутрибольничного переноса резистентной микробной флоры в настоящем исследовании были поставлены следующие задачи:

1. Изучить микробный пейзаж двух практически независимых ОРИТ одной больницы с учетом следующих факторов: антибиотикорезистентности, распространения во внешней среде и биологических средах, динамики изменений (с интервалом $6 \mathrm{Mec})$.

2. Изучить генетические особенности превалирующих бактерий.

3. Проследить динамику смены микроорганизмов у пациентов, переведенных в конкретное ОРИТ из других отделений и иных больниц.

\section{Материалы и метолы}

\section{Данные о пациентах и характере образцов}

В двух реанимационных отделениях ФГАУ ЛРЦ Минздрава РФ, хирургическом ОРИТ и нейрореанимации, был проведен сбор образцов микрофлоры в течение двух временных периодов: ноябрь-декабрь 2018 и май-июнь 2019.

В хирургическом ОРИТ проходили лечение пациенты после абдоминальных и торакальных хирургических 
вмешательств, в нейрореанимации - после нейрохирургических вмешательств. Наблюдали пациентов как с неосложненным течением послеоперационного периода, так и с осложнениями, в том числе септическими. В оба отделения также поступали пациенты, переводимые из других лечебных учреждений.

Возможность перемещения больных, персонала и оборудования между двумя ОРИТ практически полностью была ограничена общебольничным персоналом и приборами для эндоскопии. Исключением были единичные случаи перевода больных из нейрореанимации в хирургическое ОРИТ для проведения гемодиафильтрации.

Образцы, проанализированные в ходе исследования, представляли собой мокроту из дистальных участков трахебронхиального дерева (полученную при бронхоскопии), раневое отделяемое, кровь и мочу, а также смывы с медицинской одежды и рук персонала, эндоскопического оборудования, инфузионных стоек, постелей, медицинских карт, фонендоскопов, аппаратов ИВЛ, дозаторов жидкого мыла, тонометрических манжет, процедурных столов и пр. Все образцы подвергнуты фенотипическому и молекулярно-генетическому анализу.

\section{Фенотипический анализ}

Фенотипическое определение микроорганизмов проводили в диагностической лаборатории ЛРЦ Минздрава РФ при помощи систем mini API (Biomerieux) и WalkAway 40 (Dade-Baehring), действуя согласно инструкции и применяя стандартные наборы реактивов.

\section{Определение антибиотикорезистентности}

Определение чувствительности к антибиотикам, а именно цефепиму, цефтриаксону, цефуроксиму, цефотаксиму, сульперазону, амикацину, гентамицину, меропенему, имипенему, дорипенему, ципрофлоксацину, левофлоксацину, моксифлоксацину, амоксициллину+клавулановой кислоте, пиперациллину+тазобактаму, тигециклину, ко-тримоксазолу и фосфомицину проводили с помощью бактериологических анализаторов mini API (Biomerieux) и WalkAway 40 (Dade-Baehring) и поставляемых к ним коммерческих наборов в строгом соответствии с инструкцией. После этого одну колонию каждой культуры переносили в отдельную пробирку с лизирующим буфером и направляли на генотипирование в лабораторию анализа геномов НИИ Эпидемиологии и микробиологии им. Н.Ф. Гамалеи МЗ РФ [1].

\section{Выделение и амплификация ДНК}

ДНК из образцов выделяли согласно инструкции к набору реактивов "The Maxwell 16 Tissue DNA Purification Kit" на приборе "Maxwell MDX Instrument" ("Promega",
США). Для амплификации ДНК применяли следующие реактивы: Hot rescue DNA pol, 5 ед./мкл, ПЦР буфер 10х (НИИЭМ им. Н.Ф. Гамалеи, Россия), dNTP, 5 мМ (“Медиген”, Россия), праймеры (“Евроген", Россия). Для проведения MLST A.baumannii, K. pneumoniae, P. aeruginosa использовали следующие схемы [4], [8], [10]. Программы амплификации соответствовали авторским.

\section{Мультилокусное секвенирование (MLST)}

Генотипирование штаммов проводили согласно методике MLST. Секвенирование ПЦР продуктов выполняли согласно протоколу к набору BigDye Terminator 3.1 Cycle Sequencing kit на геномном анализаторе Genetic Analyzer 3130 ("Applied Biosystems/Hitachi", США). Электрофоретическое разделение продуктов реакции проводили в капиллярах длиной 50 см с использованием полимера POР7. Анализ последовательностей и выравнивание выполняли с помощью программы CLUSTALW2. Для определения аллельного профиля штаммов использовали программную базу следующих сайтов: $P$. aeruginosa [http:// pubmlst.org/paeruginosa], K. Pneumoniae [http://bigsdb. web.pasteur.fr/K./K.html],A.baumannii [http://pubmlst.org/ abaumannii]. Анализ данных MLST проводили, используя пакеты программ BURST [12], SplitsTree [14] и MEGA 6 [23].

В связи с тем, что схема MLST секвенирования включает в себя 7 мишеней для каждого микроорганизма, реализация её в полной мере была бы чрезвычайно экономически затратной. Более того, вариабельность микроорганизмов по различным мишеням значительно отличалась. В связи с этим была проведена работа по определению наиболее перспективных мишеней для генотипирования, анализ по которым с одной стороны обеспечивал бы максимальную информативность, а с другой не был бы избыточным. В результате этого для идентификации изолятов $K$. pneumoniae использовали последовательность фрагмента гена $r p o B$, кодирующего $\beta$ субъединицу РНК-полимеразы, и последовательность фрагмента гена tonB (В субъединица периплазматического переносчика энергии). Для идентификации изолятов A.baumannii использовали последовательность фрагмента гена $g y r B$ (субъединица В ДНК - гиразы) $и$ recA (рекомбиназа А). Для идентификации изолятов $P$. aeruginosa использовали последовательность фрагмента генов trpE (I компонент антралит синтетазы), pps (фосфоенолпируват синтетаза), и acs (ацетил коэнзим А синтетаза) в соответствии с [26].

\section{Результаты}

\section{1. Фенотипическая характеристика микроорганизмов в динамике}

Всего за время исследований были идентифицированы микроорганизмы из 101 образца. На от- 


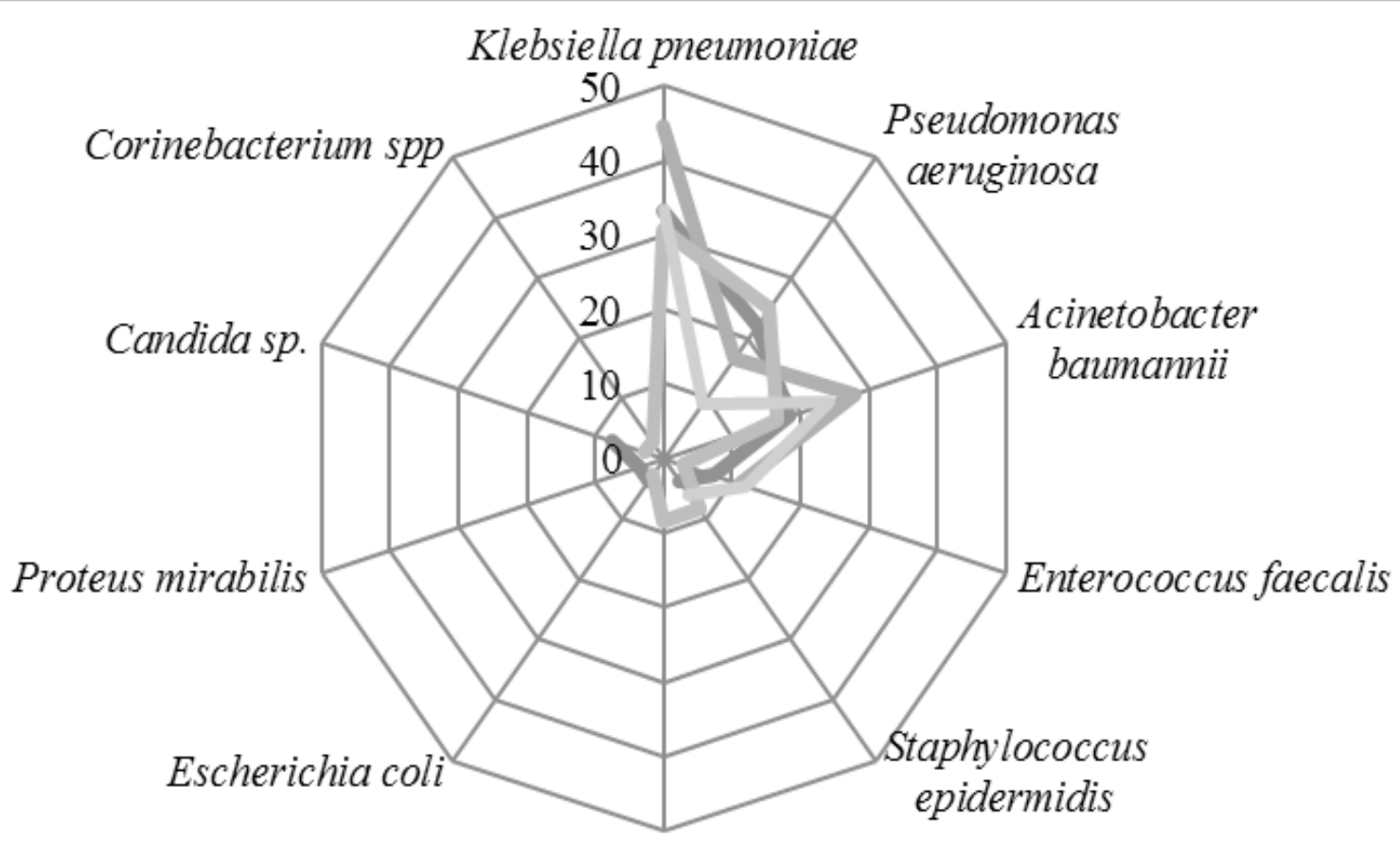

Staphylococcus aureus

Рис. 1. Представленность микроорганизмов в отделениях реанимации в 2018-2019 годах.

Удалением от центра показано количество проб. Разными цветами отмечены разные временные периоды (с начала 2018 по конец 2019 года).

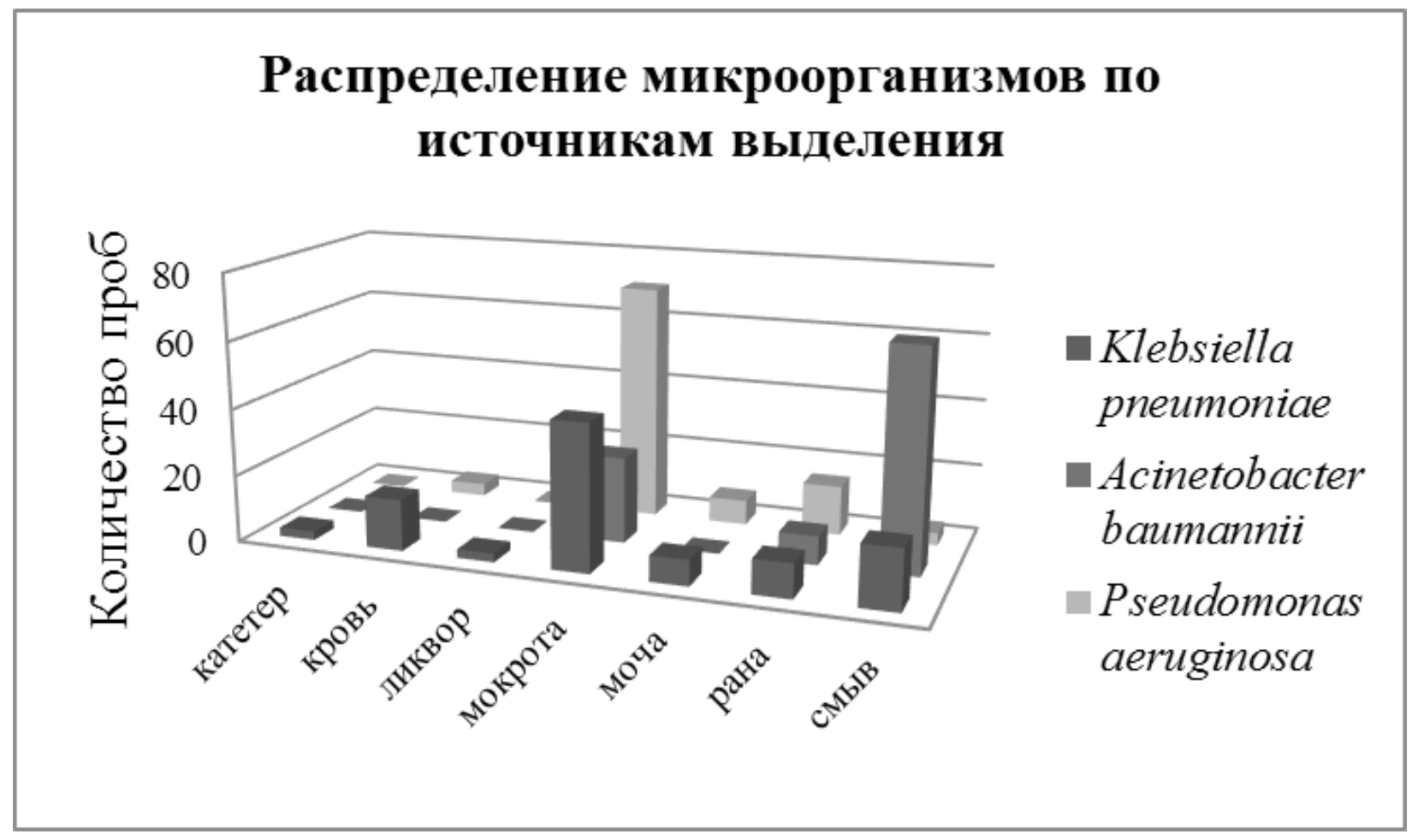

Рис. 2. Распределение микроорганизмов по источнику их выделения. Цветом обозначен микроорганизм. 


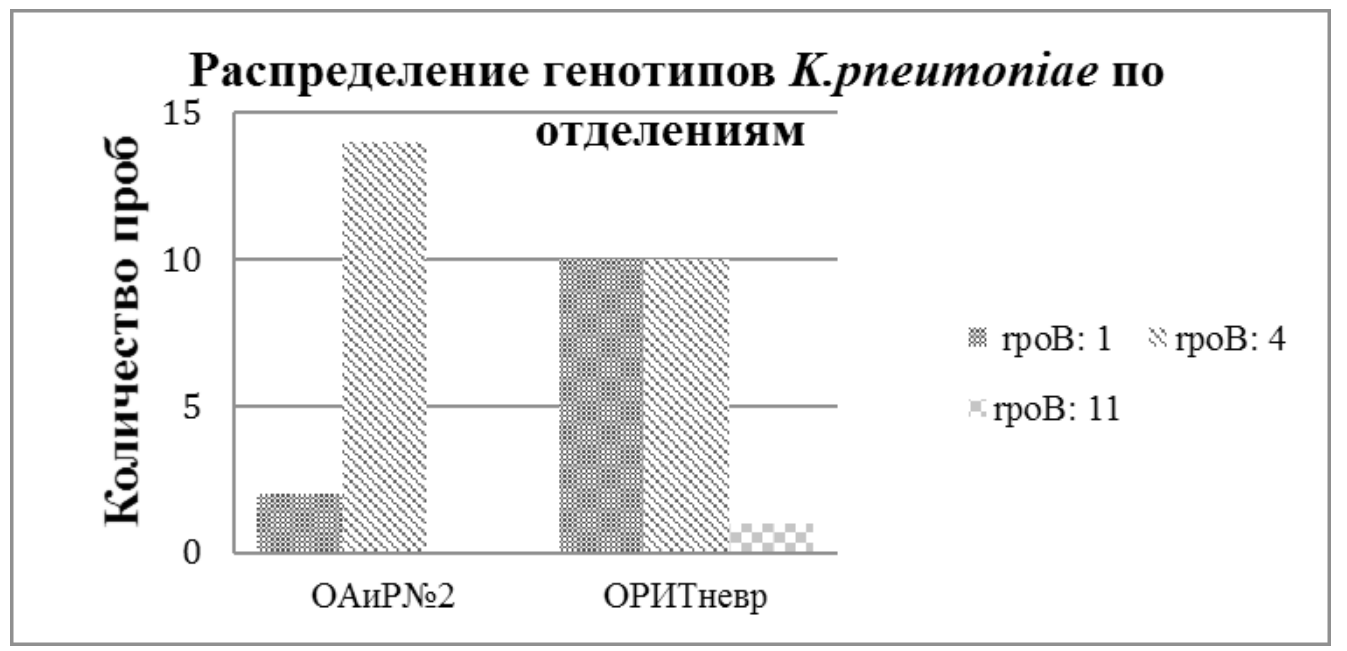

Рис. 3. Распределение генотипов $K$. pneumoniae по отделениям.

деление нейрореанимации пришлось 47\% проб, на хирургическое ОРИТ - 53\% образцов. При этом выявлены микроорганизмы 9 родов: группы ESKAPE, Candida и Corinebacterium. 73\% всех культур микроорганизмов составляли бактерии подгруппы KAP: K. pneumoniae, A. Baumannii, P. Aeruginosa (Рис. 1). Именно поэтому данная подгруппа была выбрана для углубленного анализа. Сравнение частоты представленности бактерий данной подгруппы в разные периоды исследования показали, что существенная динамика отсутствовала.

Образцы, проанализированные в ходе исследования, представляли собой фрагменты тканей, раневое отделяемое, кровь, биологические жидкости, такие как ликвор и моча, а также смывы с одежды, рук медперсонала, смывы с объектов больничной среды.

Так, можно заметить, что микроорганизмы группы КАР неравномерно распределились между источниками. K. pneumoniae, как видно из рисунка 3, обнаруживали во всех источниках, но наиболее часто в мокроте (44\%). A. baumannii ни разу не был выявлен в крови или ликворе, но определялся повсеместно на объектах внутрибольничной среды и смывах с одежды и рук медперсонала. P. aeruginosa значительно реже определяли в смывах, в 70\% случаев данный микроорганизм обнаруживали в мокроте пациентов.

Ни $K$. pneumoniae, ни $P$. aeruginosa практически не были обнаружены в объектах внешней среды (18\% и $4 \%$ соответственно), что дает возможность сделать предположение о преимущественной роли аэрогенного механизма распространения этих микроорганизмов в стационаре. Примечательно, что нами не установлено ни одного факта высева патогенной микрофлоры с эндоскопического оборудования.
Обращало также внимание, что в случае высева A. baumannii из биологической жидкости, он ни разу не был выявлен в крови, моче или цереброспинальной жидкости, а только в мокроте и в раневом содержимом.

В обоих отделениях уровни резистентности к антибиотикам указанных микроорганизмов не менялись при сравнении данных 2018 и 2019 года (данные не представлены из-за ограниченного объема статьи).

\section{2. Генотипический анализ микроорганизмов}

Генотипирование культур КАР, проведенное по оптимизированной схеме, показало, что наименьшее разнообразие генотипов продемонстрировали культуры K. Pneumoniae. Выявлены 3 генотипа в контексте гена rроВ. Использование второй мишени, гена tonB, не усилило дифференцировку. Преобладали штаммы с генотипами гроB:4 и гроB:1.

При анализе распределения генотипов микроорганизмов по отделениям реанимации установлено, что в каждом отделении преобладали штаммы с определенным генотипом. Так, в хирургическом ОРИТ среди $K$. pneumoniae значительно чаще определяли генотип rpoB: 4 (в 88\% случаев). И только в $13 \%$ случаев - rpoB:1. При этом в нейрореанимации генотипы гров: 1 и rров: 4 встречались с одинаковой частотой (Рис. 2).

Сходным образом выглядела и картина распределения генотипов $A$. baumannii. В хирургическом ОРИТ превалировал генотип gyr $B: 17$. Остальные встречались значительно реже. В отделении нейрореанимации генотип gyrB: 17 был гораздо менее распространен. 


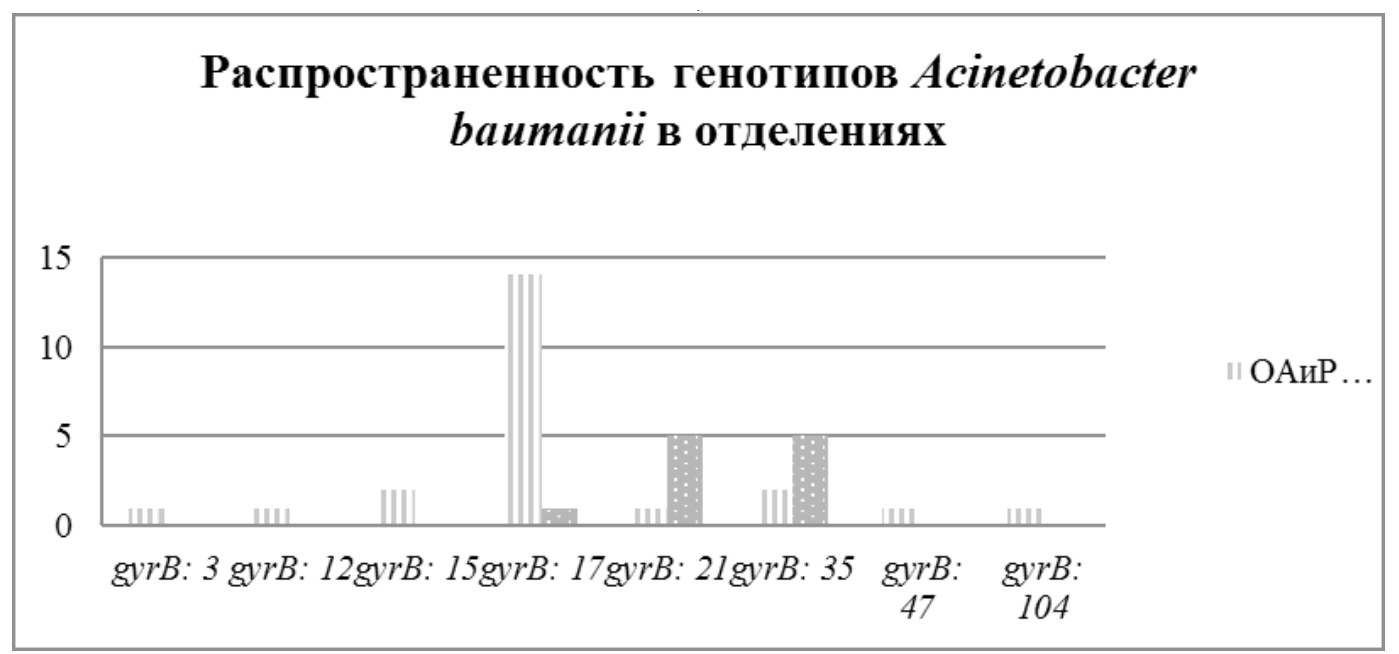

Рис. 4. Распространенность генотипов $A$. baumannii в отделениях.

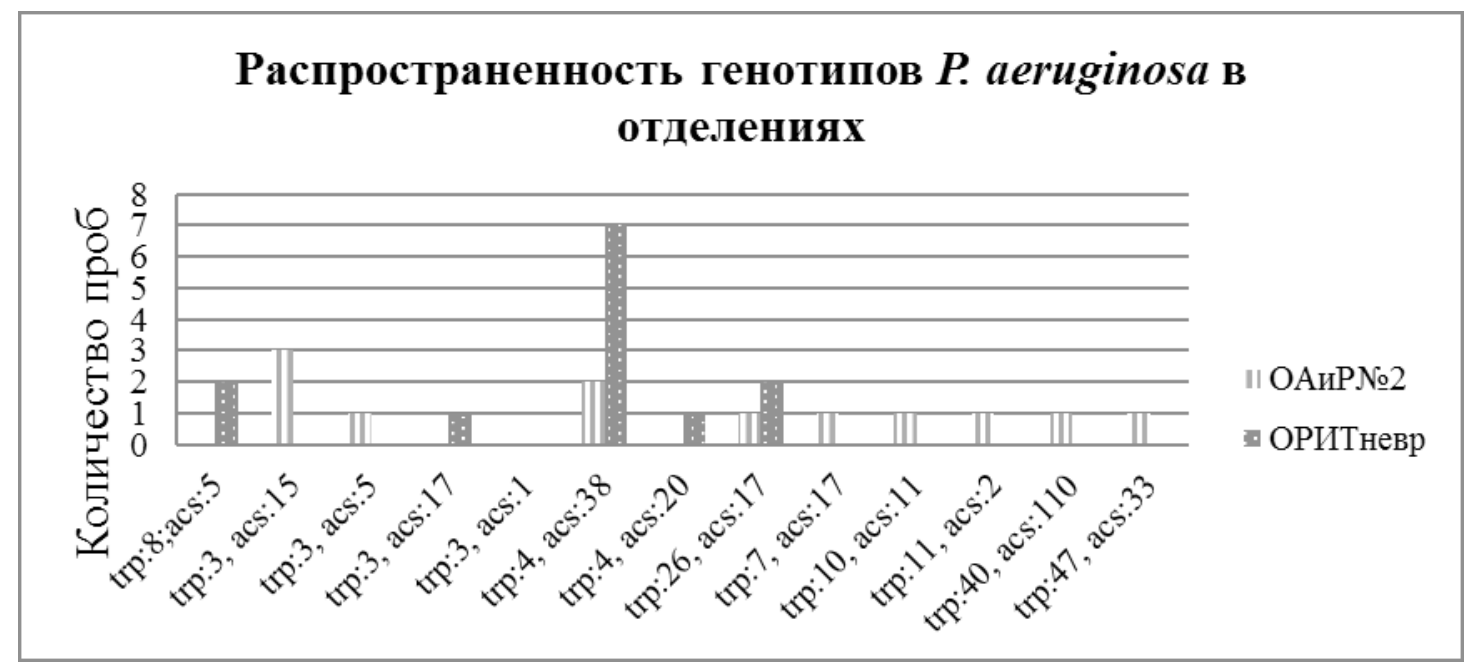

Рис. 5. Распространенность генотипов $P$. aeruginosa в отделениях.

Среди культур A. baumannii было выявлено суммарно 8 вариантов по мишени gyr $B$. Анализ, проведенный по мишени rec $A$, фактически не выявил разнообразия. Были определены лишь два варианта, один из которых выявили однократно. Среди представителей вида A. baumannii превалировали штаммы трех генотипов: gyr 17, gyr 21, gyr 35.

Наибольшее разнообразие генотипов было обнаружено при исследовании культур $P$. aeruginosa: 9 вариантов по мишени $\operatorname{trp} E, 10$ вариантов по мишени $\operatorname{acs} A$ и 2 варианта по мишени ppsA. Наиболее распространенным и часто выявляемым генотипом был trp $4 \operatorname{acs} 38$

Здесь превалировали генотипы gyrB:21 и gyrB:35. (Рис. 3)
Несколько отличалась ситуация с $P$. aeruginosa. Cpeди исследованных микроорганизмов рода Pseudomonas наблюдали большую, по сравнению с другими родами вариабельность генотипов. В хирургическом ОРИТ было представлено множество генотипов, тогда как в отделении нейроренанимации выделялся преобладающий генотип - trp4 acs 38 (в 80\% случаев) - Рис. 4.

\section{3. Анализ чувствительности микроорганизмов к действию антибиотиков в зависимости от генотипа штамма.}

Анализ чувствительности штаммов $K$. pneumoniae, A. baummanii, P. aeruginosa выделенных лабораторией ЛРЦ Минздрава РФ, к действию антимикробных препаратов показал, что данные штаммы характеризовались 


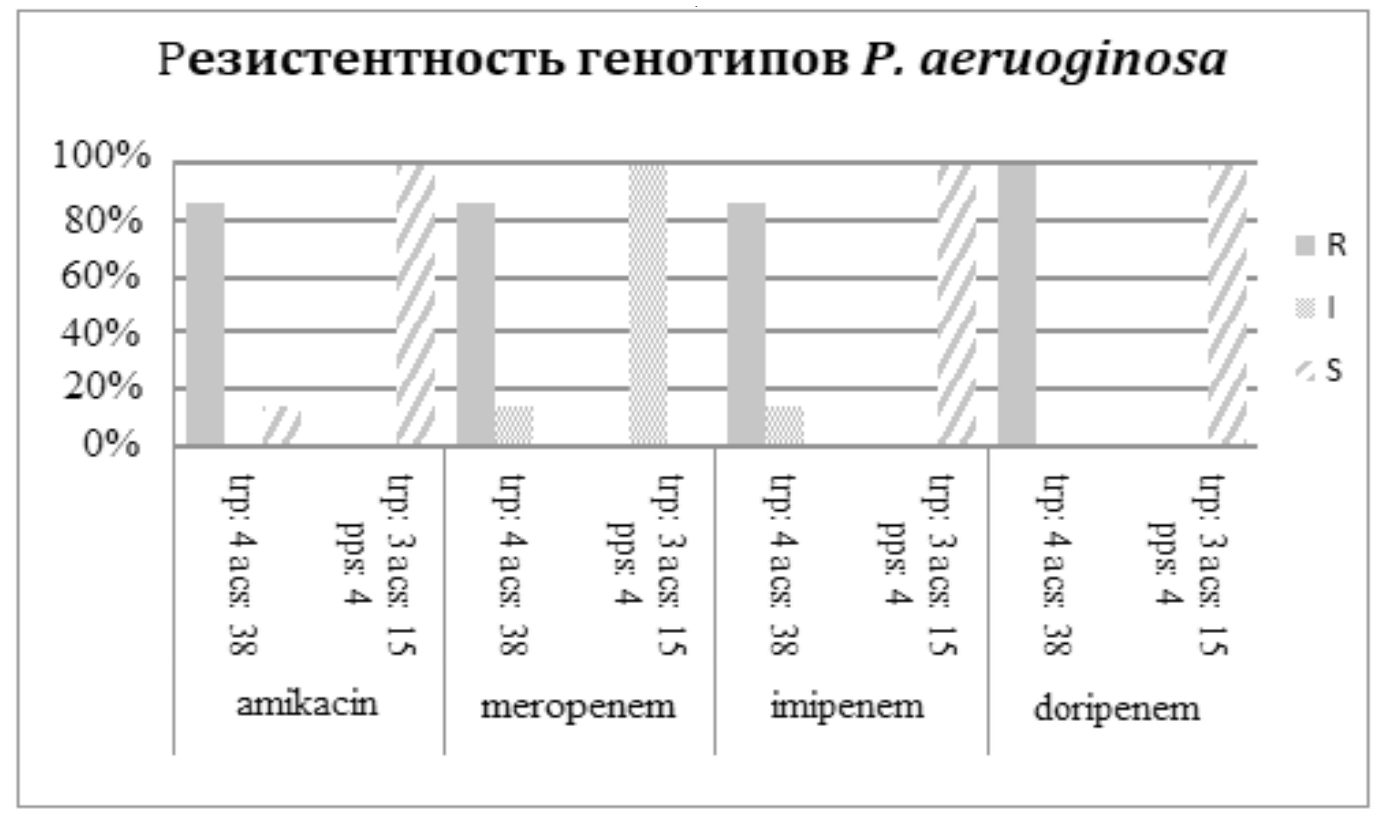

Рис. 6. Показана резистентность различных генотипов $P$. aeruginosa по отношению к действию препаратов различных групп. Цветом обозначена степень чувствительности. S - штамм чувствителен, I - штамм относительно устойчив, R - штамм устойчив. По горизонтальной оси расположены названия антибиотиков, в отношении которых проводился тест, и генотипы микроорганизма.

\section{Резистентность генотипов К. рпеитопіае}

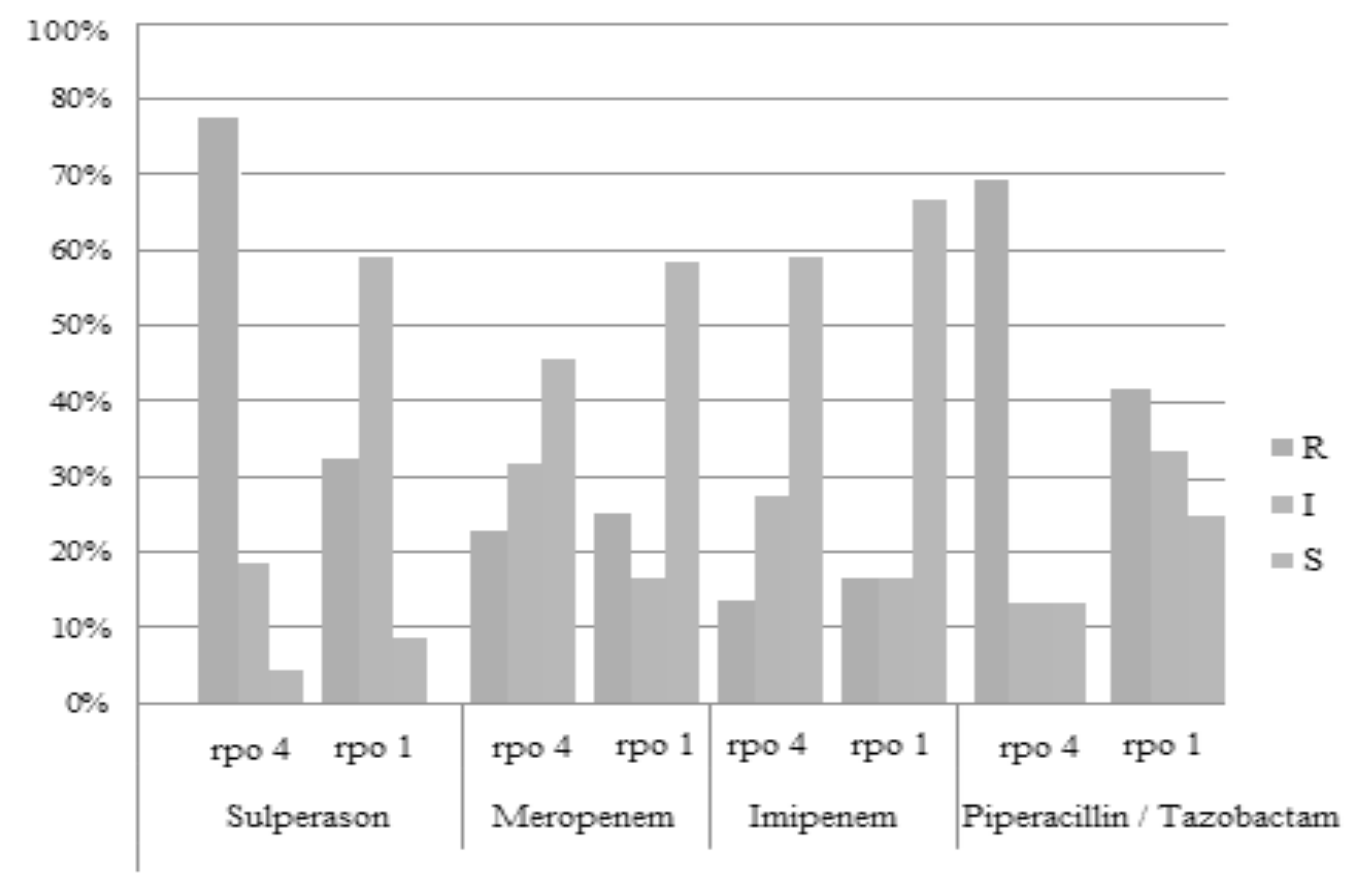

Рис 7. Среди генотипов K. Рпеитопіае штаммы гро В: 4 были более резистентны к действию сульперазона, чем rрoB: 1. В то же время генотип rроB: 1 был значительно более у стойчив к фосфомицину и более чувствителен к пиперацициллину/тазобактаму 


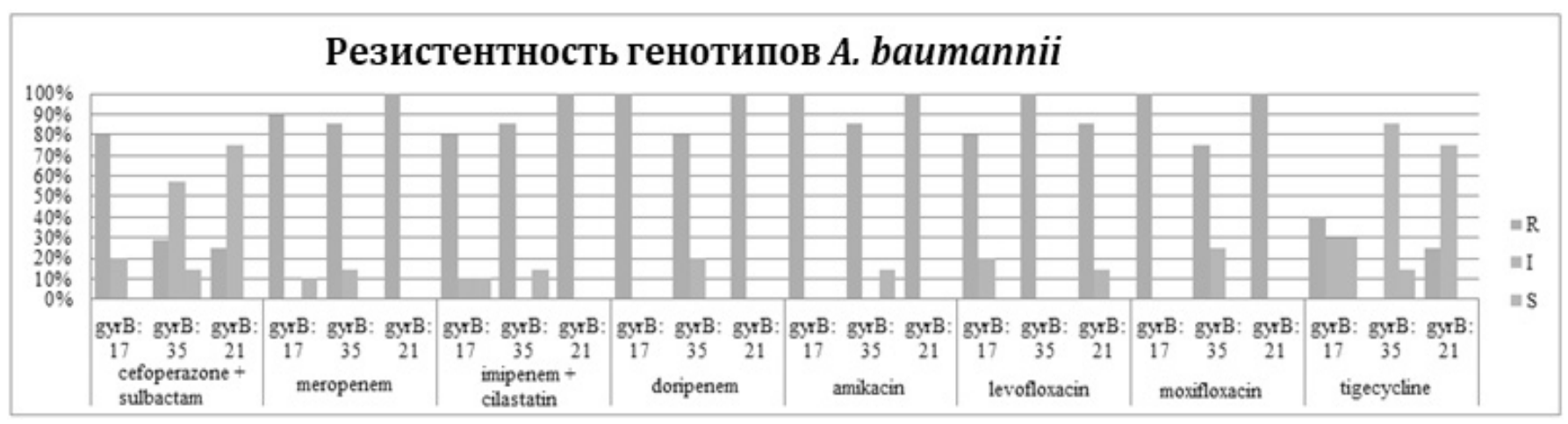

Рис 8. Устойчивость различных геноитпов A.baumannii к дейтсвию антибиотиков. Уровень резистентности указан цветом. S - чувствителен, I - относительно устойчивый, R - устойчивый.

Антибиоитики и игенотипы указаны в нижней части рисунка, в горизонтальном ряду.

множественной лекарственной устойчивостью. Установлена серьезная разница в чувствительности штаммов с различающимися генотипами к действию отдельных препаратов.

Ситуация с резистентностью представителей $P$. aeruginosa наиболее наглядна. Разные генотипы одного и того же вида демонстрировали принципиально различные уровни антибиотикорезистентности. Так наиболее распространенный штамм с генотипом trp 4 acs 38 обладал множественной лекарственной устойчивостью, в частности к карбапенемам. В то же время штаммы с другими генотипами этого не демонстрировали (рис 6).

Среди всех генотипов $A$. baumannii наиболее резистентным был gyrB: 21. За всё время исследования ни в одном тесте он не показал уровня чувствительносити S ни к одному из тестируемых антибитиков. Генотипы gyrB: 17 u gyrB: 35 были менее резистентны. Между gyrB: 17 и gyrB: 35 не было обнаружено существенных отличий в спектрах чувствительности.

\section{4. Анализ возможности распространения микроорганизмов, «внешних» по отношению к данному ОРИТ}

За время сбора материала у нас была возможность наблюдать несколько случаев «заноса» нетипичных для данного ОРИТ микроорганизмов группы КАР. Рассмотрим два случая «заноса» из другого лечебного учреждения.

1. У пациента $X$, поступившего в хирургическое ОРИТ из ЦРБ Московской области, из мокроты были выделены нетипичные для ЛРЦ изоляты $A$. baumannii gyrB: 3 u gyrB: 47, которые в дальнейшем ни разу не были выявлены ни у этого пациента, ни у других больных.

2. У пациента У, поступившего из г. Когалым в отделение нейрореанимации, из мокроты был выде- лен штамм $K$. pneumoniae с характерным для ЛРЦ генотипом гров: 1, но с нетипичной низкой резистентностью. Впоследствии в пробах более не обнаруживали столь чувствительные к антибиотикам штаммы K. pneumoniae.

Мы также наблюдали несколько случаев внутрибольничного переноса:

1. В хирургическом ОРИТ у пациента Z в мокроте определили $A$. baumannii gyrB: 21 recA:32, который ранее у пациентов этого отделения не обнаруживали, зато определяли во многих пробах из больничной среды в отделении нейрореанимации. Штамм с таким генотипом удалось выделить в хирургическом ОРИТ лишь однократно.

2. После дежурства в отделении нейрореанимации в смывах с костюма и с рук врача А. был выделен типичный для этого отделения генотип $A$. baumannii gyrB: $35 \mathrm{rec} A$ : 2. В этот же день аналогичный штамм $A$. baumannii gyrB: 35 rec $A$ : 2 был обнаружен у пациента В из хирургического ОРИТ. До этого случая штаммы A. baumannii с таким генотипом в этом отделении отсутствовали. Не определялись они и в последующем.

Точные пути переноса штаммов нам установить не удалось в обоих случаях.

За всё время исследования не было выявлено случаев, когда у одного и того же пациента одномоментно или в одном и том же месте взятия смыва одномоментно определялись разные генотипы и/или комбинации генотипов.

\section{$\triangle и с к у с с и я$}

Анализ полученных нами данных показал, что в обоих отделениях, как в хирургическом ОРИТ, так и в ней- 
рореанимации, доминировала Грам-минус флора: $K$. pneumoniae, A. Baumannii, P. Aeruginosa. Все микроорганизмы подгруппы КАР демонстрировали полирезистентность. K. Pneumoniae u P. Aeruginosa преимущественно выделяли из биологических жидкостей, A. Baumannii - со смывов объектов внешней среды. В динамике (2018 и 2019 гг) существенной разницы в составе выделяемых бактерий не обнаружено. Это вполне согласуется с данными исследования, также анализировавшего распространение нозокомиальной флоры с течением времени [5].

Преобладание Грам-минус флоры совпадает с данными других авторов и характерно для РФ и Европы [3], [22]. Совпадают и результаты изучения антибиотикорезистентности - она высокая. Фактически не было ни одной бактерии с гарантированной чувствительностью к конкретному антибиотику. Данный факт подчеркивает необходимость использования как минимум двух АБ против потенциальных возбудителей, по меньшей мере на старте АБ -терапии [21].

Распространение в биологических жидкостях и окружающей среде подчеркивают необходимость ужесточения контроля над переносом высоко патогенных штаммов. С эпидемиологической точки зрения перенос K. Pneumoniae u P. Aeruginosa может быть ограничен временным полным закрытием ОРИТ (аналогично тактике временного закрытия родильных домов). Данная мера не предупредит распространение A. Baumannii, который может быть уничтожен только тщательной обработкой окружающей среды, включая одежду персонала и используемые им приборы.[6]. Верно и обратное. Тщательная обработка внешней среды не предупреждает перенос K. Pneumoniae u P. Aeruginosa, определяемого недостаточной асептикой манипуляций.

Отсутствие динамики в течение 9 мес в микробном пейзаже обоих отделений реанимации заставляет предполагать, что локальная микрофлора формирует достаточно стабильный биоценоз. В то же время, преимущественное выделение в обоих реанимационных отделениях полирезистентных микроорганизмов подгруппы КАР могло быть основанием для предположения об их идентичности и необходимости поиска путей внутрибольничного переноса.

Однако данное предположение не подтвердилось анализом генома выделенных штаммов. Несмотря на схожесть фенотипических характеристик микроорганизмов и в целом высокий уровень устойчивости к АБ, оказалось, что для каждого ОРИТ было характерно преобладание локальных, «аборигенных» генетических штаммов. С точки зрения проведения АБ-терапии это имеет некоторое значение, поскольку между штаммами с разным генотипом имеется разница в чувствительности к антибиотикам. Гораздо большее значение найденный факт имеет с эпидемиологической точки зрения, поскольку заставляет усомниться в значимости внутрибольничного переноса резистентных штаммов (между разными отделениями) Эти данные также согласуются с результатами некоторых других исследователей, также не отметивших эпидемиологически-значимых случаев внутрибольничного переноса [15]. Соответственно, вызывает сомнение эффективность эпидемиологических мероприятий такого рода. Это предположение подтверждает отсутствие выделения микрофлоры с эндоскопической аппаратуры, а также анализ динамики штаммов у переводных пациентов. Как в случае «заноса» из другой больницы, так и при внутрибольничном переносе «ввозимые» пациентом или переносимые персоналом штаммы «не задерживались» в отделении и быстро замещались «аборигенами» данного ОРИТ. При этом наиболее распространенные штаммы микроорганизмов подгруппы КАР, которым свойственно преобладание в отделении и длительное существование в стационаре, характеризовались значительно большей лекарственной устойчивостью, по сравнению с привнесёнными штаммами.

Полученные факты подчеркивают важность микробиологического мониторинга в конкретном ОРИТ для назначения рациональной АБ-терапии по меньшей мере у длительно находящихся в отделении пациентов. Знание особенностей «аборигенной» микрофлоры позволяет достаточно уверенно предполагать наиболее вероятный фенотип и генотип микроорганизма уже на старте АБ-терапии (даже при отсутствии «свежих» посевов от конкретного больного). Хотя, учитывая растущую скорость и доступность результатов генотипирования в ряде случаев может оказаться более рациональным использовать данные методы и в рутинной клинической практике, и для принятия решения о выборе антибиотика, не ограничиваясь лишь ретроспективными исследованиями [7].

В заключении остановимся на недостатках нашей работы. Тщательность генетического анализа не позволила нам компенсировать методологические проблемы, связанные с недостаточной выборкой пациентов, переводившихся из других стационаров. В этой связи выводы о вытеснении привнесенных штаммов «аборигенными» являются лишь предварительными.

Нужно также учесть, что при работе на анализаторах WalkAway 40 компании Dade-Baehrinп и miniApi компании Biomerieux возможно озникновение ошибок в определении уровней антибиотикорезистентности. Автоматические анализаторы обеих названных фирм обладают достаточно высокой чувствительностью и специфичностью для их применения в клинической практике, которая не всегда 
достаточна для проведения эпидемиологических исследований [27]. Отмечено, что анализаторам свойственны ошибки, они с вероятностью до 5\% определяют устойчивый штамм, как чувствительный, и с вероятностью до 2535\% чувствительный штамм, как устойчивый [17],[16]. Отдельные исследования отмечают ложную чувствительность при определении резистентности к карбапенемам, другие - ложную устойчивость [11], [13]. В литературе есть данные об определении устойчивых к действию тигециклина штаммов как чувствительных [9], [25].

\section{Зак^ючение}

1. В процессе функционирования ОРИТ в нем формируется патогенная микрофлора, типичная для конкретного отделения. Данная микрофлора имеет специфические генетические характеристики и мало меняется в течение длительного времени.

2. Внешние фенотипические характеристики микроорганизмов - морфология и устойчивость к АБ, не являются гарантией их одинакового генотипа в разных ОРИТ.

3. Перевод пациентов из других отделений и других лечебных учреждений вероятнее всего не имеет существенного значения с точки зрения потенциального изменения преобладающей Грам-минус флоры конкретного ОРИТ.

4. Наиболее перспективны эпидемиологические мероприятия, направленные на предупреждение переноса бактерий в пределах конкретного ОРИТ. Для профилактики переноса K. pneumoniae и P. Aeruginosa важнейшими являются меры личной гигиены персонала, для A. Baumannii - первостепенное значение имеет тщательная обработка предметов окружающей среды.

5. АБ-терапия длительно находящихся в реанимационном отделении пациентов может и должна строиться с учетом микробного пейзажа конкретного ОРИТ и характерной для локальных микроорганизмов чувствительности к АБ.

\section{ЛИТЕРАТУРА}

1. Воронина 0.Л., Чернуха М.Ю., Шагинян И.А., Кунда М.С., Аветисян Л.Р., Орлова А.А., Лунин В.Г., Авакян Л.В., Капранов Н.И., Амелина Е.Л., Чучалин А.Г., Гинцбург А.Л. Характеристика генотипов штаммов Burkholderia серасіа complex, выделенных от больных в стационарах российской федерации. // Мол. генет. микробиол. вирусол. - 2013.— № 2-C. 20-30.

2. Козлов Р.С., Стецюк 0.У., Андреева И.В. // Интенсивная терапия. - 2007. № 4. - С. $217-226$.

3. Angeletti S, Cella E, Prosperi M, Spoto S, Fogolari M, De Florio L, Antonelli F, Dedej E, De Flora C, Ferraro E, Incalzi RA, Coppola R, Dicuonzo G, Francescato F, Pascarella S, Ciccozzi M. Multi-drug resistant Pseudomonas aeruginosa nosocomial strains: Molecular epidemiology and evolution. Microb Pathog. 2018 0ct;123:233-241. doi: 10.1016/j.micpath.2018.07.020. Epub 2018 Jul 19. PMID: 30031889.

4. Bartual SG, Seifert H, Hippler C, Luzon MA, Wisplinghoff H, Rodríguez-Valera F. Development of a multilocus sequence typing scheme for characterization of clinical isolates of Acinetobacter baumannii. J Clin Microbiol. 2005 Sep;43(9):4382-90. doi: 10.1128/JCM.43.9.4382-4390.2005. Erratum in: J Clin Microbiol. 2007 Jun;45(6):2101. PMID: 16145081; PMCID: PMC1234098.

5. Bedenić B, Beader N, Godič-Torkar K, Vranić-Ladavac M, Luxner J, Veir Z, Grisold AJ, Zarfel G. Nursing Home as a Reservoir of Carbapenem-Resistant Acinetobacter baumannii. Microb Drug Resist. 2015 Jun;21(3):270-8. doi: 10.1089/mdr.2014.0157. Epub 2015 Jan 19. PMID: 25599131.

6. Bedenić B, Siroglavić M, Slade M, Šijak D, Dekić S, Musić MŠ, Godan-Hauptman A, Hrenović J. Comparison of clinical and sewage isolates of Acinetobacter baumannii from two long-term care facilities in Zagreb; mechanisms and routes of spread. Arch Microbiol. 2020 Mar;202(2):361-368. doi: 10.1007/s00203-019-01750-9. Epub 2019 0ct 30. PMID: 31667533.

7. Boronina LG, Samatova EV, Kukushkina MP, Blinova SM, Panova SA, Ustyugova SS. Search for an optimal test algorithm and characteristic of carbapenemases in nosocomial strains. Klin Lab Diagn. 2020 Dec 29;65(12):771-777. English. doi: 10.18821/0869-2084-2020-65-12-771-777. PMID: 33373509.

8. Brisse S, Fevre C, Passet V, Issenhuth-Jeanjean S, Tournebize R, Diancourt L, Grimont P. Virulent clones of Klebsiella pneumoniae: identification and evolutionary scenario based on genomic and phenotypic characterization. PLoS One. 2009;4(3): e4982. doi: 10.1371/journal.pone.0004982. Epub 2009 Mar 25. PMID: 19319196; PMCID: PMC2656620.

9. Casal M, Rodríguez F, Johnson B, Garduno E, Tubau F, de Lejarazu RO, Tenorio A, Giménez MJ, Bartolomé R, Garcia-Rey C, Aguilar L, García-Escribano N. Influence of testing methodology on the tigecycline activity profile against presumably tigecycline-non-susceptible Acinetobacter spp. J Antimicrob Chemother. 2009 Jul;64(1):69-72. doi: 10.1093/jac/dkp169. Epub 2009 May 17. PMID: 19451133.

10. Curran B, Jonas D, Grundmann H, Pitt T, Dowson CG. Development of a multilocus sequence typing scheme for the opportunistic pathogen Pseudomonas aeruginosa. J Clin Microbiol. 2004 Dec;42(12):5644-9. doi: 10.1128/JCM.42.12.5644-5649.2004. PMID: 15583294; PMCID: PMC535286.

11. Färber J, Moder KA, Layer F, Tammer I, König W, König B. Extended-spectrum Beta-lactamase detection with different panels for automated susceptibility testing and with a chromogenic medium. J Clin Microbiol. 2008 Nov;46(11):3721-7. doi: 10.1128/JCM.00777-08. Epub 2008 Sep 24. Erratum in: J Clin Microbiol.2009 Jan;47(1):285. PMID: 18845821; PMCID: PMC2576589.

12. Feil EJ, Holmes EC, Bessen DE, Chan MS, Day NP, Enright MC, Goldstein R, Hood DW, Kalia A, Moore CE, Zhou J, Spratt BG. Recombination within natural populations of pathogenic bacteria: short-term empirical estimates and long-term phylogenetic consequences. Proc Natl Acad Sci U S A. 2001 Jan 2;98(1):182-7. doi: 10.1073/ pnas.98.1.182. Erratum in: Proc Natl Acad Sci U S A 2001 Mar 27;98(7):4276. PMID: 11136255; PMCID: PMC14565. 
13. Fernández F, Martínez L, Pascual A, Perea EJ. Falsa resistencia a imipenema en bacilos gramnegativos mediante un sistema automatizado [False resistance to imipenem in gram negative bacilli with and automatized system]. Enferm Infecc Microbiol Clin. 2000 Dec;18(10):500-5. Spanish. PMID: 11198000.

14. Huson DH. SplitsTree: analyzing and visualizing evolutionary data. Bioinformatics. 1998;14(1):68-73. doi: 10.1093/bioinformatics/14.1.68. PMID: 9520503.

15. Johansson E, Welinder-Olsson C, Gilljam M, Pourcel C, Lindblad A. Genotyping of Pseudomonas aeruginosa reveals high diversity, stability over time and good outcome of eradication. J Cyst Fibros. 2015 May;14(3):353-60. doi: 10.1016/j.jf.2014.09.016. Epub 2014 0ct 30. PMID: 25458462.

16. Juretschko S, Labombardi VJ, Lerner SA, Schreckenberger PC; Pseudomonas AST Study Group. Accuracies of beta-lactam susceptibility test results for Pseudomonas aeruginosa with four automated systems (BD Phoenix, MicroScan WalkAway, Vitek, and Vitek 2). JClin Microbiol. 2007 Apr;45(4):1339-42. doi: 10.1128/JCM.0171606. Epub 2007 Jan 17. PMID: 17229867; PMCID: PMC1865858.

17. Kulah C, Aktas E, Comert F, Ozlu N, Akyar I, Ankarali H. Detecting imipenem resistance in Acinetobacter baumannii by automated systems (BD Phoenix, Microscan WalkAway, Vitek 2); high error rates with Microscan WalkAway. BMC Infect Dis. 2009 Mar 16;9:30. doi: 10.1186/1471-2334-9-30. PMID: 19291298; PMCID: PMC2664816.

18. Magiorakos AP, Srinivasan A, Carey RB, Carmeli Y, Falagas ME, Giske CG, Harbarth S, Hindler JF, Kahlmeter G, Olsson-Liljequist B, Paterson DL, Rice LB, Stelling J, Struelens MJ, Vatopoulos A, Weber JT, Monnet DL. Multidrug-resistant, extensively drug-resistant and pandrug-resistant bacteria: an international expert proposal for interim standard definitions for acquired resistance. Clin Microbiol Infect. 2012 Mar;18(3):268-81. doi: 10.1111/j.1469-0691.2011.03570.x. Epub 2011 Jul 27. PMID: 21793988.

19. Marra AR, Edmond MB. Hand Hygiene: State-of-the-Art Review With Emphasis on New Technologies and Mechanisms of Surveillance. Curr Infect Dis Rep. 2012 Dec;14(6):585-91. doi: 10.1007/s11908-012-0288-y. PMID: 22922997.

20. Ochoa SA, Escalona G, Cruz-Córdova A, Dávila LB, Saldaña Z, Cázares-Domímguez V, Eslava CA, López-Martínez B, Hernández-Castro R, Aquino-Jarquin G, XicohtencatlCortes J. Molecular analysis and distribution of multidrug-resistant Enterococcus faecium isolates belonging to clonal complex 17 in a tertiary care center in Mexico City. BMC Microbiol. 2013 Dec 11;13:291. doi: 10.1186/1471-2180-13-291. PMID: 24330424; PMCID: PMC4029522.

21. Pachori $P$, Gothalwal $R$, Gandhi P. Emergence of antibiotic resistance Pseudomonas aeruginosa in intensive care unit; a critical review. Genes Dis. 2019 Apr 17;6(2):109-119. doi: 10.1016/j.gendis.2019.04.001. PMID: 31194018; PMCID: PMC6545445.

22. Pérez-Vázquez M, Sola Campoy PJ, Ortega A, Bautista V, Monzón S, Ruiz-Carrascoso G, Mingorance J, González-Barberá EM, Gimeno C, Aracil B, Sáez D, Lara N, Fernández S, González-López JJ, Campos J, Kingsley RA, Dougan G, Oteo-Iglesias J; Spanish NDM Study Group. Emergence of NDM-producing Klebsiella pneumoniae and Escherichia coli in Spain: phylogeny, resistome, virulence and plasmids encoding blaNDM-like genes as determined by WGS. J Antimicrob Chemother. 2019 Dec 1;74(12):3489-3496.

23. Tamura K, Stecher G, Peterson D, Filipski A, Kumar S. MEGA6: Molecular Evolutionary Genetics Analysis version 6.0. Mol Biol Evol. 2013 Dec;30(12):2725-9. doi: 10.1093/molbev/mst197. Epub 2013 0ct 16. PMID: 24132122; PMCID: PMC3840312.

24. Tang SS, Apisarnthanarak A, Hsu LY. Mechanisms of $\beta$-lactam antimicrobial resistance and epidemiology of major community-and healthcare-associated multidrugresistant bacteria. Adv Drug Deliv Rev. 2014 Nov 30;78:3-13. doi: 10.1016/j.addr.2014.08.003. Epub 2014 Aug 16. PMID: 25134490.

25. Tejero R, Causse M, Moreno M, Solís F, Rodríguez-López F, Casal M. Evaluación de la variabilidad en la sensibilidad de Acinetobacter baumannii a tigeciclina en un mismo medio de cultivo con dos métodos de difusión cuantitativos comerciales diferentes [Evaluation of the variability in the susceptibility of Acinetobacter baumannii to tigecycline in the same medium with two methods of quantitative diffusion different commercial]. Rev Esp Quimioter. 2012 Sep;25(3):189-93. Spanish. PMID: 22987264.

26. This publication made use of the A.baumanniiMLST website (http://pubmlst.org/ abaumannii/) sited at the University of Oxford (Jolley \& Maiden 2010, BMC Bioinformatics, 11. - P. 595). The development of this site has been funded by the Wellcome Trust.

27. Winstanley T, Courvalin P. Expert systems in clinical microbiology. Clin Microbiol Rev. 2011 Jul;24(3):515-56. doi: 10.1128/CMR.00061-10. PMID: 21734247; PMCID: PMC3131062.

(с Аврамов Александр Александрович ( avramovmsu@gmail.com ),

Царенко Сергей Васильевич ( S9637501492@уandex.ru ), Зинина Елизавета Павловна ( epzinina@gmail.com ).

Журнал «Современная наука: актуальные проблемы теории и практики» 